\title{
Inverse association of des-acyl ghrelin with worksite blood pressure in overweight/obese male workers
}

\author{
Akihiko Narisada Tomomi Hasegawa - Maki Nakahigashi \\ Takaaki Hirobe $\cdot$ Tatsunori Ikemoto • Takahiro Ushida • \\ Fumio Kobayashi
}

Received: 22 December 2014/ Accepted: 23 February 2015/Published online: 10 March 2015

(C) The Japanese Society for Hygiene 2015

\begin{abstract}
Background Job strain, defined as a combination of high job demands and low job control, has been reported to elevate blood pressure (BP) during work. Meanwhile, a recent experimental study showed that ghrelin blunted the BP response to such mental stress. In the present study, we examined the hypothesis that des-acyl ghrelin may have some beneficial effects on worksite BP through modulating the BP response to work-related mental stress, i.e., job strain.

Methods Subjects were 34 overweight/obese male dayshift workers (mean age $41.7 \pm 6.7$ years). No subjects had received any anti-hypertensive medication. A 24-h ambulatory BP monitoring was recorded every $30 \mathrm{~min}$ on a regular working day. The average $\mathrm{BP}$ was calculated for Work BP, Morning BP, and Home BP. Job strain was assessed using the short version of the Japanese Job Content Questionnaire.

Results Des-acyl ghrelin showed significant inverse correlations with almost all BPs except Morning SBP, Morning DBP, and Home DBP. In multiple regression analysis, des-acyl ghrelin inversely correlated with Work SBP after adjusting for confounding factors. Des-acyl ghrelin was also negatively associated with BP changes from Sleep to Morning, Sleep to Work, and Sleep to Home.
\end{abstract}

\footnotetext{
A. Narisada ( $\square)$ - T. Hasegawa · M. Nakahigashi · T. Hirobe · F. Kobayashi

Department of Health and Psychosocial Medicine, Aichi

Medical University School of Medicine, 1-1 Yazakokarimata,

Nagakute, Aichi 480-1195, Japan

e-mail: akihikonarisada@yahoo.co.jp

T. Hasegawa $\cdot$ T. Ikemoto $\cdot$ T. Ushida

Institute of Physical Fitness, Sports Medicine and Rehabilitation,

Aichi Medical University, Nagakute, Japan
}

Conclusions Des-acyl ghrelin was inversely associated with Worksite BP, suggesting a unique beneficial effect of des-acyl ghrelin on Worksite BP in overweight/obese male day-shift workers.

Keywords Worksite blood pressure - Des-acyl ghrelin · Job strain · Obesity · Ambulatory blood pressure monitoring

\section{Introduction}

High job strain, defined as a combination of high job demands and low job control at work [1], has been reported to elevate blood pressure (BP) during work $[2,3]$. This association between high job strain and high worksite BP is rather remarkable in obese workers compared with nonobese workers [3, 4]. In addition, BP elevation by mental stress through the autonomic nervous system (ANS) activity [5] was strengthened by obesity [6-8], insulin resistance [6], and metabolic syndrome (Mets) [9].

Ghrelin, originally known as a growth hormone $(\mathrm{GH})$ releasing peptide from the stomach [10], circulates in acylated and des-acylated forms [11]. Des-acyl ghrelin, which is the most abundant form (about $90 \%$ ), is devoid of GH releasing capacity and does not stimulate food intake [11]. However, it has been indicated that relatively low levels of des-acyl ghrelin [12] might contribute to obesity, insulin resistance, and Mets [13-16]. Yano et al. [15, 17] indicated, in recent epidemiological studies, that low circulating des-acyl ghrelin levels are involved in arteriosclerosis and cardiovascular disease events in elderly hypertensive people. Des-acyl ghrelin might have additional beneficial effects on the cardiovascular system [12] through different mechanism, such as improving 
endothelial function [18], ANS activity [19], and BP [20]. A recent experimental study also showed that ghrelin blunted the BP response to mental stress [21].

Based on these findings, we hypothesized that des-acyl ghrelin might have some beneficial effects on worksite BP through modulating the BP response to work-related mental stress, i.e., high job strain. In this study, we focused on the relations of plasma des-acyl ghrelin levels with worksite BP and BP change to worksite BP.

\section{Methods}

\section{Subjects}

Fifty-five overweight/obese [body mass index (BMI) $\geqq 25 \mathrm{~kg} \mathrm{~m}^{-2}$ ] male workers who participated in a weight reduction program conducted by Aichi Medical University Institute of Physical Fitness, Sports Medicine and Rehabilitation, were enrolled. The protocol of the study, which was approved by the Ethical Committee at Aichi Medical University, was explained in detail, and written informed consent was obtained from each subject. All of them were regular employees at several small- and medium-sized enterprises, with 10-300 employees. Ten subjects with incomplete measurements of their 24-h ambulatory BP monitoring (ABPM), one subject who worked under a shift work system including a night shift, 8 subjects receiving anti-hypertensive medication, and 2 subjects with poor recording of Holter electrocardiogram were excluded. Finally, 34 subjects, aged from 27 to 58 years (mean age, $41.7 \pm 6.7$ years), were examined.

\section{Procedure}

Subjects had physical examinations including blood sampling in the morning after an overnight fast. Height and weight were measured, and BMI was calculated as weight $(\mathrm{kg}) /$ height $(\mathrm{m})^{2}$. After subjects had been sitting quietly for $5 \mathrm{~min}$, BP was measured 3 times with a fully automated sphygmomanometer (TM-2655; A\&D, Tokyo, Japan). The average of the $3 \mathrm{BP}$ measurements was calculated as Rest BP. Medical history, current therapeutic regime, smoking state, and alcohol consumption were queried using a selfreporting questionnaire. Smoker was defined as current smokers. Alcohol drinker was defined as a subject drinking alcohol of more than $20 \mathrm{~g}$ /day.

Twenty-four hour ABPM and 2-channel 24-h ambulatory electrocardiographic (ECG) were conducted on a regular working day. BP was automatically recorded every 30 min with a portable BP measuring device (TM-2431; A\&D, Tokyo, Japan). The methods of ABPM measurement and the criteria for identifying BP measurement errors complied with the Guidelines for the Clinical Use of 24 Hour ABPM by the Japanese Circulation Society [22]. Subjects were also asked to record their activities in a diary throughout the BP measurement. Based on these activity logs, we calculated Worksite BP, Morning BP, and Home $\mathrm{BP}$ as follows: Worksite BP was the average during work, Morning BP was the average during the first $2 \mathrm{~h}$ after waking up, and Home BP was the average from getting home in the evening to going to bed.

The heart rate variability (HRV) was analyzed on a Holter analysis system (ML analyzer; Medi Link, Toyota, Japan). The digitized $\mathrm{R}-\mathrm{R}$ intervals were recorded and stored, and the power spectral densities were computed using the maximum entropy method (MEM). The power spectral densities were analyzed in 3 areas of concentration of spectral power by means of MEM. In these 2 areas, lowfrequency power (LF: $0.04-0.15 \mathrm{~Hz}$ ) was analyzed as an index of sympathetic and parasympathetic nervous system activity, and high-frequency power (HF: $0.15-0.4 \mathrm{~Hz}$ ) was analyzed as an index of parasympathetic nervous system activity. The ratio of LF to HF (LF/HF), an indirect index of sympathetic nervous system activity [23], was calculated for each data set.

Plasma glucose was analyzed in duplicate using the hexokinase method. Serum insulin was measured using the chemiluminescence enzyme immunoassay method. Hemoglobin A1c (HbA1c) was measured by the latex agglutination method.

To measure the des-acyl ghrelin level, a fasting venous sample was collected into a syringe containing EDTA-2Na $\left(1.25 \mathrm{mg} \mathrm{ml}^{-1}\right)$ and aprotinin. Plasma was obtained by centrifuging the whole blood for $15 \mathrm{~min}$ at $4{ }^{\circ} \mathrm{C}$, and was immediately frozen and stored at $-40{ }^{\circ} \mathrm{C}$ until analysis. Des-acyl ghrelin levels were measured using a two-site sandwich enzyme-linked immunosorbent assay (ELISA) kit (Mitsubishi Chemical Medience, Tokyo, Japan) according to the manufacturer's instructions. The Homeostasis Model Assessment score of insulin resistance (HOMA-R) was calculated with the following formula: fasting insulin $\left(\mathrm{mU} \mathrm{ml}^{-1}\right) \times$ fasting glucose $\left(\mathrm{mmol} \mathrm{l}^{-1}\right) /$ 405. All blood sample analyses were performed in the same laboratory (SRL, Nagoya, Japan).

Job strain, as defined by the job demands/control model [1], was measured by the Japanese short version of the Job Content Questionnaire (JCQ). The short version of JCQ measured three job demand items (work hard, demands for extra work, and insufficient time to perform work) and three items of job control (work at own pace, personal choice in the approach to work, and being able to incorporate one's own opinions to the workplace policies). All questions were scored on a Likert scale of 1-4. Job demand and job control scores were calculated by the sums of those item's scores. Each score for job demands and job control was 
dichotomized by the median split into two groups (high and low). The high job strain group was defined as having both a score above the median for job demands (high job demands) and below the median for job control (low job control). Physical activity at work was classified into 'sedentary work' or 'not sedentary work' according to the self-reported behavior description diary. Sedentary work was defined as more than $80 \%$ of working time doing desk work. Sleep state was assessed using the Japanese version of the Pittsburgh Sleep Quality Index (PSQI) [24, 25]. Poor sleep condition was defined as PSQI $>5.5[24,25]$.

Statistical analysis

Data are expressed as mean $\pm \mathrm{SD}$. After examining the normality of distribution in all numerical variables using Shapiro-Wilk test, plasma des-acyl ghrelin levels, LF, HF, LF/HF, and HOMA-R were logarithmically transformed. Spearman's correlation coefficients were calculated to determine associations of des-acyl ghrelin with the other variables including BPs. We used unpaired $t$ test to compare differences in variables including BPs and des-acyl ghrelin between subjects with or without job strain. Correlations between des-acyl ghrelin and BP in the 3 individual activities, i.e., Work, Home, and Morning were examined using multiple linear regression analysis adjusting for awake value of $\mathrm{LF} / \mathrm{HF}$ and rest BP. To evaluate the effect of des-acyl ghrelin on BP changes, we examined the associations of des-acyl ghrelin with BP differences [22] calculated by subtracting Sleep BP from Work, Home, and Morning BPs, and by subtracting Work BP from Home and Morning BPs, using multiple linear regression analysis. Statistical significance was defined as $P<0.05$. SPSS 21.0 for Windows (SPSS Tokyo, Japan) was used for the statistical analysis.

\section{Results}

The characteristics of subjects are presented in Table 1 . The median job demand score was 9, and the median job control score was also 9. The high job strain group, therefore, had job demand scores above 9 and job control scores below 9. Twenty-four subjects were overweight, defined as $30 \mathrm{~kg} \mathrm{~m}^{-2}>\mathrm{BMI} \geq 25 \mathrm{~kg} \mathrm{~m}^{-2}$, and ten subjects were obese, defined as $\mathrm{BMI} \geq 30 \mathrm{~kg} \mathrm{~m}^{-2}$; twelve subjects had hypertension, defined as rest $\mathrm{BP} \geq 140$ / $90 \mathrm{~mm} \mathrm{Hg}$; and two subjects had diabetes mellitus, defined as $\mathrm{HbA} 1 \mathrm{c} \geq 6.5 \%$ or fasting glucose $\geq 126 \mathrm{mg} \mathrm{dl}^{-1}$. None of the subjects had anti-diabetic treatment.

Table 2 shows Spearman's correlation coefficients between des-acyl ghrelin and the other variables. Des-acyl ghrelin was negatively correlated with waist circumference,
Table 1 Descriptive characteristics of study subjects

\begin{tabular}{|c|c|}
\hline Characteristics & $n=34$ \\
\hline Age (years) & $41.7 \pm 6.7$ \\
\hline Weight (kg) & $84.8 \pm 12.6$ \\
\hline BMI $\left(\mathrm{kg} \mathrm{m}^{-2}\right)$ & $29.0 \pm 3.4$ \\
\hline Waist circumference $(\mathrm{cm})$ & $96.3 \pm 8.2$ \\
\hline Rest SBP (mmHg) & $134.5 \pm 18.7$ \\
\hline Rest DBP (mmHg) & $84.8 \pm 13.8$ \\
\hline 24-h SBP (mmHg) & $139.1 \pm 14.2$ \\
\hline 24-h DBP (mmHg) & $85.2 \pm 11.4$ \\
\hline Morning SBP (mmHg) & $140.3 \pm 16.5$ \\
\hline Morning DBP (mmHg) & $88.0 \pm 14.0$ \\
\hline Worksite SBP (mmHg) & $147.4 \pm 15.5$ \\
\hline Worksite DBP (mmHg) & $90.5 \pm 12.6$ \\
\hline Home SBP (mmHg) & $145.4 \pm 18.3$ \\
\hline Home DBP (mmHg) & $87.9 \pm 12.5$ \\
\hline Sleep SBP $(\mathrm{mmHg})$ & $120.9 \pm 16.8$ \\
\hline Sleep DBP (mmHg) & $75.6 \pm 12.6$ \\
\hline 24-h average heart beat (bpm) & $80.5 \pm 6.3$ \\
\hline 24-h LF & $544.6 \pm 423.1$ \\
\hline 24-h HF & $186.2 \pm 205.2$ \\
\hline 24-h LF/HF & $3.8 \pm 2.5$ \\
\hline Awake value of LF & $508.0 \pm 407.5$ \\
\hline Awake value of $\mathrm{HF}$ & $125.3 \pm 171.6$ \\
\hline Awake value of $L F / H F$ & $5.5 \pm 2.8$ \\
\hline Des-acyl ghrelin $\left(\mathrm{pmol}^{-1}\right)$ & $179.3 \pm 87.4$ \\
\hline Glucose $\left(\mathrm{mg} \mathrm{dl}^{-1}\right)$ & $100.2 \pm 13.0$ \\
\hline Insulin $\left(\mu \mathrm{U} \mathrm{ml}^{-1}\right)$ & $9.8 \pm 4.6$ \\
\hline HOMA-R & $2.5 \pm 1.3$ \\
\hline HbA1c $(\%)$ & $5.2 \pm 0.6$ \\
\hline Current smoker, $n(\%)$ & $11(32.4)$ \\
\hline Alcohol drinker, $n(\%)$ & $10(29.4)$ \\
\hline Job demand score & $9.2 \pm 2.0$ \\
\hline Job control score & $8.9 \pm 2.2$ \\
\hline Job strain, $n(\%)$ & $8(23.5)$ \\
\hline Sedentary work, $n(\%)$ & $15(44.1)$ \\
\hline Poor sleep condition, $n(\%)$ & $14(41.2)$ \\
\hline
\end{tabular}

$B M I$ body mass index, $S B P$ systolic blood pressure, $D B P$ diastolic blood pressure, $L F$ low-frequency power, $H F$ high-frequency power, $L F / H F$ ratio of low- to high-frequency power, HOMA-R the homeostasis model assessment of insulin resistance, HbAlc hemoglobin A1c

and positively correlated with $24 \mathrm{~h}$ of LF, awake value of LF, and awake value of HF. It also showed significant inverse correlations with almost all BPs except Morning SBP, Morning DBP, Work DBP, Home DBP, and Sleep SBP.

Table 3 presented the comparison of physiological parameters between the two job strain groups, i.e. with and without job strain. There were no significant differences between the two groups both in BPs and in plasma des-acyl ghrelin levels. 
Table 2 Spearman's correlation coefficients $(r)$ between des-acyl ghrelin and other anthropometric, hemodynamic, heart rate variability, and metabolic parameters

\begin{tabular}{|c|c|c|}
\hline & $r$ & $P$ \\
\hline Age & -0.325 & 0.061 \\
\hline Weight & -0.225 & 0.201 \\
\hline BMI & -0.300 & 0.085 \\
\hline Waist circumference & -0.376 & 0.028 \\
\hline Rest SBP & -0.429 & 0.011 \\
\hline Rest DBP & -0.409 & 0.016 \\
\hline 24-h SBP & -0.437 & 0.010 \\
\hline 24-h DBP & -0.428 & 0.012 \\
\hline Morning SBP & -0.258 & 0.141 \\
\hline Morning DBP & -0.231 & 0.189 \\
\hline Worksite SBP & -0.474 & 0.005 \\
\hline Worksite DBP & -0.312 & 0.073 \\
\hline Home SBP & -0.393 & 0.021 \\
\hline Home DBP & -0.186 & 0.291 \\
\hline Sleep SBP & -0.268 & 0.125 \\
\hline Sleep DBP & -0.348 & 0.044 \\
\hline 24-h LF & 0.378 & 0.028 \\
\hline 24-h HF & 0.308 & 0.076 \\
\hline 24-h LF/HF & 0.053 & 0.768 \\
\hline Awake value of LF & 0.360 & 0.037 \\
\hline Awake value of $\mathrm{HF}$ & 0.362 & 0.035 \\
\hline Awake value of $\mathrm{LF} / \mathrm{HF}$ & 0.043 & 0.808 \\
\hline HOMA-R & -0.168 & 0.342 \\
\hline
\end{tabular}

$r$ means Spearman's correlation coefficients

$B M I$ body mass index, $S B P$ systolic blood pressure, $D B P$ diastolic blood pressure, $L F$ low-frequency power, $H F$ high-frequency power, $L F / H F$ ratio of low- to high-frequency power, HOMA-R the homeostasis model assessment of insulin resistance

In multiple regression analysis, des-acyl ghrelin was significantly correlated with Work SBP after adjusting for awake value of LF/HF and Rest SBP (Table 4).

Table 5 shows multiple regression analysis for evaluating the effect of des-acyl ghrelin on BP changes from Sleep to Work, from Sleep to Home, and from Sleep to Morning. After adjusting variables, a significant inverse association was observed between des-acyl ghrelin and SBP change from Sleep to Work. There were no significant associations between des-acyl ghrelin and the other BP changes from Sleep. Table 5 presents significant negative correlations of des-acyl ghrelin with SBP changes from Morning to Work, and from Work to Home in multiple regression analysis.

\section{Discussion}

A significant inverse correlation of plasma des-acyl ghrelin levels with Worksite SBP was observed in Japanese overweight/obese male day-shift workers (Tables 2, 3). Des-acyl ghrelin was also negatively associated with the difference subtracting Sleep BP from Work BP (Table 5). In addition, significant inverse correlations between desacyl ghrelin and SBP changes from Morning to Work, and from Work to Home (Table 5). These results suggested that des-acyl ghrelin might have some beneficial effects on BP during work.

Des-acyl ghrelin was positively correlated with awake value of HF (Table 2), which is considered an index of parasympathetic nervous system activity. This result is in agreement with an animal experimental study which indicated that des-acyl ghrelin affected parasympathetic nervous system activity [19]. Lambert et al. [21] showed, in their experimental study, that ghrelin administration blunted BP response to mental stress with task load. It is therefore probable that des-acyl ghrelin has a sort of buffering effect on BP elevation caused by mental stress, such as job strain during work.

In this study, des-acyl ghrelin was not associated with Home SBP, while it inversely correlated with Work SBP. Home SBP might be strongly affected by a variety of home-related stressors [26], resulting in such an insignificant correlation as found in the study.

We measured des-acyl ghrelin but not acyl ghrelin in this study for a technical reason. It is well known that the acyl ghrelin level is parallel to that of des-acyl ghrelin [27], and that acyl ghrelin has unique beneficial cardiovascular effects [28, 29], such as improving ANS (sympathetic nervous system) and BP. Thus, the results of our study might have been confounded by the effect of acyl ghrelin. In this regard, future study should clarify the effects of the two types of ghrelin separately.

Recent studies have indicated that mental stress could affect circulating levels of ghrelin and the acylated enzyme of ghrelin, ghrelin- $O$-acyltransferse [30, 31]. On the other hand, it has been suggested that ghrelin affects the psychological state, such as anti-depressive symptoms [30]. Rouach et al. [32] showed, in their experimental study in humans, that the stress-induced increase in ghrelin was associated with the increase in cortisol, but not the increase in BP. This result suggests that ghrelin is not influenced by stress-induced BP changes directly. Further research is warranted to examine these complex relationships among mental stress, including job strain, BP, and acyl or des-acyl ghrelin.

In several interventional studies, regular exercise programs without caloric restriction raised levels of the total and the des-acyl ghrelin $[33,34]$, a reaction which in turn might prevent BP elevation at work. This positive effect could partially explain the hypothesis proposed by Hamer [35] that physical activity may alleviate the harmful effects of mental stress on cardiovascular disease. 
Table 3 Comparison of mean values between subjects with and without job strain
$P$ were calculated using unpaired $t$ test

$B M I$ body mass index, $S B P$ systolic blood pressure, $D B P$ diastolic blood pressure, $L F$ low-frequency power, $H F$ highfrequency power, $L F / H F$ ratio of low- to high-frequency power, HOMA-R the homeostasis model assessment of insulin resistance

\begin{tabular}{|c|c|c|c|}
\hline & With job strain $(n=8)$ & Without job strain $(n=26)$ & $P$ \\
\hline Age (years) & $43.3 \pm 6.7$ & $41.3 \pm 6.8$ & 0.474 \\
\hline BMI $\left(\mathrm{kg} \mathrm{m}^{-2}\right)$ & $29.2 \pm 2.9$ & $29.0 \pm 3.6$ & 0.866 \\
\hline Waist circumference $(\mathrm{cm})$ & $95.2 \pm 7.8$ & $96.6 \pm 8.5$ & 0.671 \\
\hline Rest SBP (mmHg) & $135.5 \pm 9.2$ & $134.2 \pm 20.9$ & 0.869 \\
\hline Rest DBP (mmHg) & $85.0 \pm 7.2$ & $84.7 \pm 15.3$ & 0.655 \\
\hline 24-h SBP (mmHg) & $134.0 \pm 14.0$ & $140.7 \pm 14.1$ & 0.244 \\
\hline 24-h DBP (mmHg) & $83.6 \pm 9.6$ & $85.7 \pm 12.0$ & 0.653 \\
\hline Morning SBP (mmHg) & $131.8 \pm 19.2$ & $142.8 \pm 15.0$ & 0.100 \\
\hline Morning DBP (mmHg) & $82.7 \pm 14.3$ & $89.6 \pm 13.7$ & 0.229 \\
\hline Worksite SBP (mmHg) & $142.5 \pm 14.7$ & $149.0 \pm 15.6$ & 0.310 \\
\hline Worksite DBP (mmHg) & $88.2 \pm 9.5$ & $91.2 \pm 13.5$ & 0.557 \\
\hline Home SBP (mmHg) & $143.4 \pm 17.7$ & $146.1 \pm 18.8$ & 0.723 \\
\hline Home DBP (mmHg) & $84.9 \pm 14.8$ & $88.8 \pm 11.8$ & 0.443 \\
\hline Sleep SBP (mmHg) & $115.7 \pm 12.6$ & $122.6 \pm 17.7$ & 0.319 \\
\hline Sleep DBP (mmHg) & $73.6 \pm 9.3$ & $76.2 \pm 13.6$ & 0.624 \\
\hline $\log 24-\mathrm{h}$ of LF & $6.3 \pm 0.8$ & $6.0 \pm 0.6$ & 0.369 \\
\hline $\log 24-\mathrm{h}$ of $\mathrm{HF}$ & $4.8 \pm 1.2$ & $4.9 \pm 0.7$ & 0.727 \\
\hline $\log 24-\mathrm{h}$ of $\mathrm{LF} / \mathrm{HF}$ & $1.5 \pm 0.7$ & $1.1 \pm 0.5$ & 0.114 \\
\hline Log awake value of LF & $6.2 \pm 0.7$ & $5.9 \pm 0.6$ & 0.331 \\
\hline Log awake value of HF & $4.5 \pm 1.0$ & $4.4 \pm 0.7$ & 0.846 \\
\hline Log awake value of LF/HF & $1.7 \pm 0.7$ & $1.5 \pm 0.5$ & 0.383 \\
\hline Log des-acyl ghrelin & $2.2 \pm 0.2$ & $2.2 \pm 0.2$ & 0.820 \\
\hline Log HOMA-R & $0.4 \pm 0.2$ & $0.3 \pm 0.2$ & 0.742 \\
\hline
\end{tabular}

Table 4 Results of multiple linear regression analysis with the Morning BP, Work BP, and Home BP as the dependent variables and des-acyl ghrelin as the independent variables, controlling for awake value of LF/HF and Rest BP

\begin{tabular}{|c|c|c|c|c|c|}
\hline & \multirow[t]{2}{*}{ B $(95 \%$ CL $)$} & \multirow[t]{2}{*}{$\beta$} & \multirow[t]{2}{*}{$P$} & \multicolumn{2}{|l|}{ Model } \\
\hline & & & & $R^{2}$ & ANOVA $p$ \\
\hline \multicolumn{6}{|c|}{ Morning BP } \\
\hline SBP & $-12.71(-41.03$ to 15.62$)$ & -0.159 & 0.364 & 0.472 & 0.023 \\
\hline DBP & $-8.30(-32.47$ to 15.87$)$ & -0.123 & 0.486 & 0.464 & 0.027 \\
\hline \multicolumn{6}{|c|}{ Work BP } \\
\hline SBP & $-54.00(-78.65$ to -29.34$)$ & -0.718 & $>0.001$ & 0.549 & 0.005 \\
\hline DBP & $-28.56(-51.26$ to -5.85$)$ & -0.467 & 0.016 & 0.422 & 0.055 \\
\hline \multicolumn{6}{|c|}{ Home BP } \\
\hline SBP & $-49.12(-83.81$ to -14.42$)$ & -0.555 & 0.007 & 0.356 & 0.140 \\
\hline DBP & $-13.50(-36.50$ to 9.51$)$ & -0.223 & 0.238 & 0.392 & 0.087 \\
\hline
\end{tabular}

Model was adjusted for log-transformed awake value of LF/HF and Rest BP

$B P$ blood pressure, $S B P$ systolic blood pressure, $D B P$ diastolic blood pressure, $L F / H F$ ratio of low- to high-frequency power

Helicobacter pylori infection, which is a gram-negative bacterium associated with gastric diseases, might be related with ghrelin and ghrelin acylation. Plasma total, acyl, and des-acyl ghrelin of Helicobacter pylori infection-positive subjects was lower than those of negative subjects $[31,36]$. However, Ando et al. [36] showed, in their clinical intervention study, that Helicobacter pylori eradication decreased plasma des-acyl ghrelin.
In human and animal experimental studies, injection of lipopolysaccharide, which is an innate defense response and is considered a hypothalamic-pituitary-adrenal axis activation, induced a rapid decrease in plasma des-acyl ghrelin levels [37].

In animal studies, abdominal surgery reduced plasma acyl and des-acyl ghrelin levels. However, the effects of abdominal surgery on des-acyl ghrelin in human are difficult to evaluate [31]. 
Table 5 Results of multiple linear regression analysis with the (A) BP changes from Sleep $\mathrm{BP}$ as the dependent variables and des-acyl ghrelin as the independent variables, controlling for awake value of LF/HF and Sleep BP (B) BP changes from Morning BP or Home BP to Work BP as the dependent variables and desacyl ghrelin as the independent variables, controlling for awake value of $\mathrm{LF} / \mathrm{HF}$ and Morning $\mathrm{BP}$ or Home BP

Model was adjusted for $\log$ transformed awake value of LF/ HF and (A) Sleep BP

(B) Morning BP or Home BP

$B P$ blood pressure, $S B P$ systolic blood pressure, $D B P$ diastolic blood pressure, $L F / H F$ ratio of low- to high-frequency power

\begin{tabular}{|c|c|c|c|c|c|}
\hline & \multirow[t]{2}{*}{ B (95 \% CL) } & \multirow[t]{2}{*}{$\beta$} & \multirow[t]{2}{*}{$P$} & \multicolumn{2}{|l|}{ Model } \\
\hline & & & & $R^{2}$ & ANOVAp \\
\hline \multicolumn{6}{|c|}{ (A) BP changes from Sleep BP } \\
\hline \multicolumn{6}{|c|}{ Morning-Sleep BP change } \\
\hline SBP & $4.72(-17.89$ to 27.45$)$ & 0.075 & 0.674 & 0.175 & 0.119 \\
\hline DBP & $-2.10(-22.85$ to 18.66$)$ & -0.040 & 0.838 & 0.055 & 0.630 \\
\hline \multicolumn{6}{|c|}{ Work-Sleep BP change } \\
\hline SBP & $-22.20(-40.45$ to -3.95$)$ & -0.379 & 0.019 & 0.383 & 0.002 \\
\hline DBP & $-6.75(-26.96$ to 8.47$)$ & -0.165 & 0.372 & 0.165 & 0.138 \\
\hline \multicolumn{6}{|c|}{ Home-Sleep BP change } \\
\hline SBP & $-10.05(-31.91$ to 11.81$)$ & -0.176 & 0.355 & 0.075 & 0.500 \\
\hline DBP & $8.62(-5.66$ to 22.90$)$ & 0.225 & 0.227 & 0.162 & 0.145 \\
\hline \multicolumn{6}{|c|}{ (B) BP changes from Morning BP or Home BP to Work BP } \\
\hline \multicolumn{6}{|c|}{ Work-Morning BP change } \\
\hline SBP & $-30.20(-48.75$ to -11.64$)$ & -0.447 & 0.002 & 0.477 & $>0.001$ \\
\hline DBP & $-15.63(-29.20$ to -2.05$)$ & -0.325 & 0.025 & 0.449 & $>0.001$ \\
\hline \multicolumn{6}{|c|}{ Work-Home BP change } \\
\hline SBP & $-19.70(-36.82$ to -2.59$)$ & -0.343 & 0.026 & 0.447 & $>0.001$ \\
\hline DBP & $-15.70(-29.35$ to -2.04$)$ & -0.374 & 0.026 & 0.268 & 0.023 \\
\hline
\end{tabular}

Many epidemiological studies have indicated that workers with high job strain have unhealthy lifestyles, such as excess alcohol consumption [38, 39], undesirable eating habits [38, 40-42], and fewer physical activities [38, 42, 43], and therefore tend to be obese [44, 45] and have Mets [46]. Thus, job strain might directly elevate Worksite BP, and obesity, or Mets with increased insulin resistance or low des-acyl ghrelin might also contribute to BP elevation.

\section{Clinical implications}

High Worksite BP or worksite (stress-induced)-masked hypertension, in which blood pressure increases during work in spite of being normotensive in a clinic, leads to target organ damage [47, 48] and is a risk for cardiovascular disease. In addition, BP variability, even awake time $\mathrm{BP}$ variability, also correlates with target organ damage [49]. It is therefore clinically important to manage stressinduced BP elevation during work. From this aspect, ghrelin could help control excessive BP elevation due to mental stress. Of the two types of ghrelin, however, acyl ghrelin is not suitable for subjects with obesity or Mets, because of its stimulating effect on food intake and reducing effect on insulin sensitivity. Des-acyl ghrelin might be a better candidate for the treatment of stress-induced hypertension in subjects with obesity-related diseases [50]. In addition, while des-acyl ghrelin infusion does not change plasma acyl ghrelin levels, it increases plasma desacyl ghrelin levels [51]. However, there are few studies about the pharmacokinetics of ghrelin.

\section{Limitations}

Our study has several limitations. First, because of the cross-sectional nature of our data, we could not infer any causality. Second, because our study was conducted only among overweight/obese male workers, caution should be used when applying its results to other groups. Third, all cardiometabolic parameters were measured only once. Finally, medication use may be potentially confounding, although our results were not changed after adjustment of these factors as covariates.

\section{Conclusion}

The plasma des-acyl ghrelin level was inversely correlated with Worksite BP. Negative associations of des-acyl ghrelin with SBP change from Sleep to Work were also observed. This preliminary study found a negative correlation between ambulatory blood pressure at work and plasma des-acyl ghrelin concentrations in obese male workers. Further studies are required to confirm these findings and to determine if raising plasma concentrations will favorably affect the blood pressure in workers.

Acknowledgments This research was supported in part by Grantsin-Aid for Scientific Research (25460820) from the Ministry of Education, Culture, Sports, Science and Technology of Japan.

Conflict of interest The authors declare that they have no conflict of interest. 


\section{References}

1. Karasek R, Baker D, Marxer F, Ahlbom A, Theorell T. Job decision latitude, job demands, and cardiovascular disease: a prospective study of Swedish men. Am J Public Health. 1981;71:694-705.

2. Rosenthal T, Alter A. Occupational stress and hypertension. J Am Soc Hypertens. 2012;6:2-22.

3. Landsbergis PA, Dobson M, Koutsouras G, Schnall P. Job strain and ambulatory blood pressure: a meta-analysis and systematic review. Am J Public Health. 2013;103:61-71.

4. Harada K, Karube Y, Saruhara H, Takeda K, Kuwajima I. Worksite hypertension is associated with obesity and family history of hypertension. Hypertens Res. 2006;29:969-76.

5. Siervo M, Wells JC, Cizza G. The contribution of psychosocial stress to the obesity epidemic: an evolutionary approach. Horm Metab Res. 2009;41:261-70.

6. Sung BH, Wilson MF, Izzo JL Jr, Ramirez L, Dandona P. Moderately obese, insulin-resistant women exhibit abnormal vascular reactivity to stress. Hypertension. 1997;30:848-53.

7. Steptoe A, Wardle J. Cardiovascular stress responsivity, body mass and abdominal adiposity. Int J Obesity. 2005;29:1329-37.

8. Carroll D, Phillips AC, Der G. Body mass index, abdominal adiposity, obesity, and cardiovascular reactions to psychological stress in a large community sample. Psychosom Med. 2008;70: 653-60.

9. Uno H, Kario K. Focus on masked workplace hypertension: the next step for perfect 24-hour blood pressure control. Hypertens Res. 2006;29:937-40.

10. Kojima M, Hosoda H, Date Y, Nakazato M, Matsuo H, Kangawa $\mathrm{K}$. Ghrelin is a growth-hormone-releasing acylated peptide from stomach. Nature. 1999;402:656-60.

11. Hosoda H, Kojima M, Matsuo H, Kangawa K. Ghrelin and desacyl ghrelin: two major forms of rat ghrelin peptide in gastrointestinal tissue. Biochem Biophys Res Commun. 2000;279: 909-13.

12. Delhanty PJD, Neggers SJ, van der Lely AJ. Ghrelin: the differences between acyl- and des-acyl ghrelin. Eur J Endocrinol. 2012;167:601-8.

13. Barazzoni R, Zanetti M, Ferreira C, Vinci P, Pirulli A, Mucci M, et al. Relationships between desacylated and acylated ghrelin and insulin sensitivity in the metabolic syndrome. J Clin Endocrinol Metab. 2007;92:3935-40.

14. Pacifico L, Poggiogalle E, Costantino F, Anania C, Ferraro F, Chiarelli F, et al. Acylated and nonacylated ghrelin levels and their associations with insulin resistance in obese and normal weight children with metabolic syndrome. Eur J Endocrinol. 2009;161:861-70.

15. Yano Y, Toshinai K, Inokuchi T, Kangawa K, Shimada K, Kario $\mathrm{K}$, et al. Plasma des-acyl ghrelin, but not plasma HMW adiponectin, is a useful cardiometabolic marker for predicting atherosclerosis in elderly hypertensive patients. Atherosclerosis. 2009;204:590-4.

16. Rodríguez A, Gómez-Ambrosi J, Catalán V, Becerril S, Sáinz N, Gil MJ, et al. Association of plasma acylated ghrelin with blood pressure and left ventricular mass in patients with metabolic syndrome. J Hypertens. 2010;28:560-7.

17. Yano Y, Nakazato M, Toshinai K, Inokuchi T, Matsuda S, Hidaka $\mathrm{T}$, et al. Circulating des-acyl ghrelin improves cardiovascular risk prediction in older hypertensive patients. Am J Hypertens. 2014;27:727-33.

18. Togliatto G, Trombetta A, Dentelli P, Baragli A, Rosso A, Granata $\mathrm{R}$, et al. Unacylated ghrelin rescues endothelial progenitor cell function in individuals with type 2 diabetes. Diabetes. 2010;59:1016-25.
19. Inoue Y, Nakahara K, Maruyama K, Suzuki Y, Hayashi Y, Kangawa $\mathrm{K}$, et al. Central and peripheral des-acyl ghrelin regulates body temperature in rats. Biochem Biophys Res Commun. 2013;430:278-83.

20. Tsubota Y, Owada-Makabe K, Yukawa K, Maeda M. Hypotensive effect of des-acyl ghrelin at nucleus tractus solitarii of rat. Neuro Report. 2005;16:163-6.

21. Lambert E, Lambert G, Ika-Sari C, Dawood T, Lee K, Chopra R, et al. Ghrelin modulates sympathetic nervous system activity and stress response in lean and overweight men. Hypertension. 2011;58:43-50.

22. JCS Joint Working Group. Guidelines for the clinical use of 24 hour ambulatory blood pressure monitoring (ABPM) (JCS 2010). http://www.j-circ.or.jp/guideline/ (In Japanese).

23. Task Force of the European Society of Cardiology and the North American Society of Pacing and Electrophysiology. Heart rate variability: standards of measurement, physiological interpretation, and clinical use. Circulation. 1996;93(5):1043-65.

24. Buysse DJ, Reynolds CF III, Monk TH, Berman SR, Kupfer DJ. The Pittsburgh sleep quality index: a new instrument for psychiatric practice and research. Psychiatry Res. 1989;28:193-213.

25. Doi Y, Minowa M, Uchiyama M, Okawa M, Kim K, Shibui K. Psychometric assessment of subjective sleep quality using the Japanese version of the Pittsburgh Sleep Quality Index (PSQI-J) in psychiatric disordered and control subjects. Psychiatry Res. 2000;97:165-72.

26. Kario K, James GD, Marion R, Ahmed M, Pickering TG. The influence of work- and home-related stress on the levels and diurnal variation of ambulatory blood pressure and neurohumoral factors in employed women. Hypertens Res. 2002;25:499-506.

27. Akamizu T, Shinomiya T, Irako T, Fukunaga M, Nakai Y, Kangawa K. Separate measurement of plasma levels of acylated and desacyl ghrelin in healthy subjects using a new direct ELISA assay. J Clin Endocrinol Metab. 2005;90:6-9.

28. Tesauro M, Schinzari F, Caramanti M, Lauro R, Cardillo C. Metabolic and cardiovascular effects of ghrelin. Int $\mathrm{J}$ Pept. 2010;2010:864342

29. Isgaard J, Granata R. Ghrelin in cardiovascular disease and atherogenesis. Mol Cell Endocrinol. 2011;340:59-64.

30. Chuang JC, Zigman JM. Ghrelin's roles in stress, mood, and anxiety regulation. Int J Pept. 2010;2010:460549

31. Stengel A, Wang L, Taché Y. Stress-related alterations of acyl and desacyl ghrelin circulating levels: mechanisms and functional implications. Peptides. 2011;32:2208-17.

32. Rouach V, Bloch M, Rosenberg N, Gilad S, Limor R, Stern N, et al. The acute ghrelin response to a psychological stress challenge does not predict the post-stress urge to eat. Psychoneuroendocrinology. 2007;32:693-702.

33. Foster-Schubert KE, McTiernan A, Frayo RS, Schwartz RS, Rajan KB, Yasui Y, et al. Human plasma ghrelin levels increase during a one-year exercise program. J Clin Endocrinol Metab. 2005;90:820-5.

34. Cederberg H, Rajala U, Koivisto VM, Jokelainen J, Surcel HM, Keinanen-Kiukaanniemi S, et al. Unacylated ghrelin is associated with changes in body composition and body fat distribution during long-term exercise intervention. Eur $\mathrm{J}$ Endocrinol. 2011;165:243-8.

35. Hamer M. Psychosocial stress and cardiovascular disease risk: the role of physical activity. Psychosom Med. 2012;74:896-903.

36. Ando T, Mizuno S, Ishida T, Kondo Y, Miki I, Yoshida M, et al. Plasma ghrelin isoforms and gastric ghrelin- $O$-acyltransferase expression are influenced by Helicobacter pylori status. Nutrition. 2012;28:967-72.

37. Stengel A, Goebel M, Wang L, Reeve JR Jr, Taché Y, Lambrecht NW. Lipopolysaccharide differentially decreases plasma acyl and 
desacyl ghrelin levels in rats: potential role of the circulating ghrelin-acylating enzyme GOAT. Peptides. 2010;31:1689-96.

38. Tsutsumi A, Kayaba K, Yoshimura M, Sawada M, Ishikawa S, Sakai K, et al. Association between job characteristics and health behaviors in Japanese rural workers. Int $\mathrm{J}$ Behav Med. 2003; 10:125-42.

39. Hiro H, Kawakami N, Tanaka K, Nakamura K. Association between job stressors and heavy drinking: age differences in male Japanese workers. Ind Health. 2007;45:415-25.

40. Kawakami N, Tsutsumi A, Haratani T, Kobayashi F, Ishizaki M, Hayashi T, et al. Job strain, worksite support, and nutrient intake among employed Japanese men and women. J Epidemiol. 2006; 16:79-89.

41. Nishitani N, Sakakibara H, Akiyama I. Eating behavior related to obesity and job stress in male Japanese workers. Nutrition. 2009;25:45-50.

42. Nomura K, Nakao M, Tsurugano S, Takeuchi T, Inoue M, Shinozaki $\mathrm{Y}$, et al. Job stress and healthy behavior among male Japanese office workers. Am J Ind Med. 2010;53:1128-34.

43. Fransson EI, Heikkilä K, Nyberg ST, Zins M, Westerlund H, Westerholm P, et al. Job strain as a risk factor for leisure-time physical inactivity: an individual-participant meta-analysis of up to 170,000 men and women: the IPD-Work Consortium. Am J Epidemiol. 2012;176:1078-89.

44. Brunner EJ, Chandola T, Marmot MG. Prospective effect of job strain on general and central obesity in the Whitehall II Study. Am J Epidemiol. 2007;165:828-37.
45. Ishizaki M, Nakagawa H, Morikawa $Y$, Honda R, Yamada Y, Kawakami N. Influence of job strain on changes in body mass index and waist circumference-6-year longitudinal study. Scand J Work Environ Health. 2008;34:288-96.

46. Chandola T, Brunner E, Marmot M. Chronic stress at work and the metabolic syndrome: prospective study. BMJ. 2006;332: $521-5$.

47. Devereux RB, Pickering TG, Harshfield GA, Kleinert HD, Denby L, Clark L, et al. Left ventricular hypertrophy in patients with hypertension: importance of blood pressure response to regularly recurring stress. Circulation. 1983;68:470-6.

48. Mancia G, Parati G. Ambulatory blood pressure monitoring and organ damage. Hypertension. 2000;36:894-900.

49. Tatasciore AL, Renda G, Zimarino M, Soccio M, Bilo G, Parati G. Awake systolic blood pressure variability correlates with target-organ damage in hypertensive subjects. Hypertension. 2007;50:325-32.

50. Tesauro M, Schinzari F, Rovella V, Di Daniele N, Lauro D, Mores N, et al. Ghrelin restores the endothelin 1/nitric oxide balance in patients with obesity-related metabolic syndrome. Hypertension. 2009;54:995-1000.

51. Tong J, Dave N, Mugundu GM, Davis HW, Gaylinn BD, Thorner MO, et al. The pharmacokinetics of acyl, des-acyl, and total ghrelin in healthy human subjects. Eur J Endocrinol. 2013;168: $821-8$. 